\title{
A case report and review of the literature: Ciprofloxacin resistant Salmonella enterica serovar Typhi in India
}

\author{
Belgode Narasimha Harish ${ }^{1}$, Godfred Antony Menezes ${ }^{1}$, Kengamuthu Sarangapani ${ }^{2}$, Subhash \\ Chandra Parija ${ }^{1}$
}

${ }^{1}$ Department of Microbiology, Jawaharlal Institute of Postgraduate Medical Education and Research (JIPMER), Pondicherry$605006{ }^{2}$ Department of Microbiology, Government General Hospital, Pondicherry-605001; India

\begin{abstract}
Background: Enteric fever is a major public health problem in India. The current treatment of choice is the fluoroquinolones. Methods: The minimum inhibitory concentration (MIC) of ciprofloxacin was determined by E-test, HIMEDIA HiComb MIC test and agar dilution.

Results: An isolate of Salmonella enterica serovar Typhi (S. Typhi) from a case of enteric fever gave a ciprofloxacin MIC of $64 \mu \mathrm{g} / \mathrm{ml}$.

Conclusions: To our knowledge there have been no reports of such high-level resistance to ciprofloxacin in S. Typhi from southern India. HIMEDIA HiComb MIC test method is an alternative to the E-test. Ciprofloxacin resistant typhoid fever responds to treatment with ceftriaxone.
\end{abstract}

Key Words: Enteric fever, Salmonella Typhi, drug resistance.

J Infect Developing Countries 2008; 2(4): 324-327.

Received 14 June 2008 - Accepted 23 July 2008

Copyright $\odot 2008$ Harish et al. This is an open access article distributed under the Creative Commons Attribution License, which permits unrestricted use, distribution, and reproduction in any medium, provided the original work is properly cited.

\section{Introduction}

Enteric fever is a global major public health problem. Almost $80 \%$ of the cases and deaths are in Asia and the rest occur mostly in Africa and Latin America [1]. Enteric fever is endemic in many developing countries, including India and, if not treated appropriately, has a mortality rate of $30 \%$. Appropriate treatment reduces the mortality rate to as low as $0.5 \%$ [2].

Specific treatment of enteric fever used to be chloramphenicol, trimethoprim-sulfamethoxazole or ampicillin. The causative organism, Salmonella enterica serovar Typhi ( $S$. Typhi) has rapidly gained resistance to these antibiotics $[3,4]$ and so fluoroquinolones, such as ciprofloxacin, became the drug of choice for the treatment of enteric fever $[5,6]$. The incidence of multidrug resistant (MDR) $S$. Typhi was as high as $60 \%$ but then declined in Pune (1999), Nagpur (2001) and Calcutta (2000) $[7,8,9]$. The resurgence of resistant strains in Ludhiana in 2002, however, is of concern [10]. A US-based study of imported strains [11] noted an increase in the number of MDR and nalidixic acid resistant S. Typhi globally (NARST), although all isolates remained sensitive to ciprofloxacin and ceftriaxone. In Bangladesh [12] there has been a reported decrease in MDR isolates with no corresponding increase in sensitive strains. For ciprofloxacin there has been an increase in MIC in strains imported into the UK [13], in Bangladesh [14], as well as in India $[15,16,17,18]$. The exact mechanism of resistance is not fully understood but various studies have found that a single mutation in the gyrA gene is sufficient to confer resistance to nalidixic acid and reduced susceptibility to fluoroquinolones. Turner et al. observed that one of the single amino acid substitutions in GyrA is sufficient for resistance to the quinolones nalidixic acid and cinoxacin, but resistance to the fluoroquinolones (gatifloxacin, ofloxacin, ciprofloxacin, enrofloxacin and moxifloxacin) requires two substitutions in GyrA and one in ParC, confirming that these three point mutations (Ser-83 $\rightarrow$ Phe or Tyr and Asp-87 $\rightarrow$ Asn in GyrA with Glu-84 $\rightarrow$ Lys in ParC) combined are sufficient to confer fluoroquinolone resistance in $S$. Typhi. The high levels of resistance observed for these triple point mutants indicate that the amino 
acid substitutions protect GyrA and ParC from relatively high concentrations of fluoroquinolones [19]. A study on Salmonella enterica serovar Paratyphi A (S. Paratyphi A) revealed that highlevel resistance to ciprofloxacin is also associated with double mutations in the DNA gyrase subunit gyrA (Ser83 $\rightarrow$ Phe and Asp87 $\rightarrow$ Gly) and a mutation in topoisomerase IV subunit parC (Ser80 $\rightarrow$ Arg) [20]. Given the variation in the susceptibility patterns reported for $S$. Typhi, it is important to constantly monitor it to provide suitable guidelines for treatment.

There have been several reports of therapeutic failure of ciprofloxacin in patients with enteric fever $[21,22]$. All these strains were interpreted as ciprofloxacin susceptible by the standard antibiotic susceptibility tests done in a clinical laboratory using the CLSI (formerly NCCLS) guidelines [23]. There was a an increase in the MIC of ciprofloxacin compared to nalidixic acid sensitive isolates, although the values were below the breakpoint of resistance $[17,24]$. S. Paratyphi A resistant to ciprofloxacin with a MIC value of $8 \mu \mathrm{g} / \mathrm{ml}$ and $32 \mu \mathrm{g} / \mathrm{ml}$ has been reported from our centre $[25,26]$. Here we report the isolation of a strain of $S$. Typhi showing high-level resistance to ciprofloxacin.

\section{Case Report}

An isolate of $S$. Typhi from a case of enteric fever was found to have a ciprofloxacin MIC of $64 \mu \mathrm{g} / \mathrm{ml}$. The strain was isolated from the blood sample of a 19-year-old male presenting with enteric fever at Government General Hospital, Pondicherry, India, in September 2007. The antimicrobial susceptibility was determined by the disc diffusion method as per the CLSI guidelines. The isolate was found to be resistant to ciprofloxacin (did not exhibit zone of inhibition), intermediate susceptible to ampicillin and susceptible to chloramphenicol, cotrimoxazole and ceftriaxone. The MIC of ciprofloxacin as determined by the E-test method (AB-Biodisk, Sweden) was found to be $>32 \mu \mathrm{g} / \mathrm{ml}$, the agar dilution method and the HIMEDIA HiComb MIC test (HIMEDIA, Mumbai, India) revealed MIC of $64 \mu \mathrm{g} / \mathrm{ml}$. This exceeds the limit set for resistance by CLSI by a large margin, which is $4 \mu \mathrm{g} / \mathrm{ml}$ [27]. The E-test, HIMEDIA HiComb MIC test and agar dilution method MICs show good concordance and interpretative agreement. $E$ test is simple, easy to perform, and a reliable method. However, its cost and limited availability in India may restrict its use. The reference agar dilution method can be used reliably in routine laboratory susceptibility testing. HIMEDIA HiComb MIC test method is an alternative to the E-test and it was used since the MIC against ciprofloxacin was crossing the upper gradient limit of concentration, $32 \mu \mathrm{g} / \mathrm{ml}$ on the Etest strips. The MIC of ofloxacin and gatifloxacin as determined by the E-test method (AB Biodisk) was found to be $>32 \mu \mathrm{g} / \mathrm{ml}$ and $8 \mu \mathrm{g} / \mathrm{ml}$ respectively.

A regimen of ciprofloxacin (500 mg orally twice daily for 10 days) was initiated. Since the patient did not respond to ciprofloxacin the treatment was switched over to ceftriaxone (1 $\mathrm{gm}$ intravenously every 12 hours) and responded within 3 days. The patient was discharged after 10 days on ceftriaxone with no relapse on follow-up.

\section{Discussion}

The strain in this study was found to be sensitive to most antibiotics except quinolones and was intermediately susceptible to ampicillin. This is unusual, but can be explained by the fact that resistance to other antibiotics is plasmid-mediated, and is independent of resistance to fluoroquinolones, which is chromosomally mediated. It is possible that the development of resistance to ciprofloxacin is due to exposure to the drug at concentrations near the MIC.

This highly resistant ciprofloxacin S. Typhi strain is still susceptible to most of the first-line antibiotics, and this is different from the other cases reported in India where S. Typhi strains are resistant to first-line antibiotics as well as fluoroquinolones [28,29,30,31].

In India, by the mid 1990s, reports began to appear of treatment failures with ciprofloxacin [32], followed by reports from 2001 onwards of rising MICs (reduced susceptibility) of ciprofloxacin for $S$. Typhi isolates [17]. In 2008 there are reports of high-level ciprofloxacin resistant Salmonella enterica from many centres in India, including ours (Table 1) [25,26,28,33-36]. This is the first report of a high-level ciprofloxacin resistant $S$. Typhi, $64 \mu \mathrm{g} / \mathrm{ml}$, from South India.

In developing countries such as India, ciprofloxacin continues to be the mainstay in the treatment of enteric fever as it is orally effective and economical. The emergence of S. Typhi highly resistant to ciprofloxacin is a cause for worry for 
both clinicians and microbiologists as well as for patients. Though fluoroquinolone resistance is chromosomally mediated, selective pressures exerted by the overuse of these drugs may see such isolates becoming more common in the future. Of interest, though, is the possibility of turning to an older drug such as co-trimoxazole for treatment, in case of susceptible isolates.

Table 1. Studies reporting high-level ciprofloxacin resistance in Salmonella enterica serovar Typhi and Paratyphi A in India.

\begin{tabular}{|c|c|c|c|c|}
\hline Serovar & $\begin{array}{l}\text { No. of } \\
\text { isolates }\end{array}$ & $\begin{array}{l}\text { Year and } \\
\text { place } \\
\text { of isolation }\end{array}$ & $\begin{array}{c}\text { MIC of } \\
\text { ciprofloxacin } \\
(\mu \mathrm{g} / \mathrm{ml})\end{array}$ & References \\
\hline S. Typhi & 3 & $\begin{array}{l}\text { 2001-2003; } \\
\text { North India }\end{array}$ & $\geq 32$ & [34] \\
\hline $\begin{array}{l}\text { S. Paratyphi } \\
\text { A }\end{array}$ & 2 & $\begin{array}{l}\text { 2001-2003; } \\
\text { North India }\end{array}$ & 8 & [34] \\
\hline $\begin{array}{l}\text { S. Paratyphi } \\
\text { A }\end{array}$ & 1 & $\begin{array}{c}2004 ; \\
\text { South India }\end{array}$ & 8 & [25] \\
\hline S. Typhi & 2 & $\begin{array}{l}\text { 2004; North } \\
\text { India }\end{array}$ & 16 & [28] \\
\hline $\begin{array}{l}\text { S. Paratyphi } \\
\text { A }\end{array}$ & 4 & $\begin{array}{l}\text { 2004-2005; } \\
\text { South India }\end{array}$ & $8-32$ & [26] \\
\hline S. Typhi & 1 & $\begin{array}{l}\text { 2005; North } \\
\text { India }\end{array}$ & 16 & [33] \\
\hline $\begin{array}{l}\text { S. Typhi, } \\
\text { S. Paratyphi } \\
\text { A }\end{array}$ & 28 & $\begin{array}{l}2005-2006 \\
\text { North India }\end{array}$ & $8-\geq 512$ & {$[35]^{*}$} \\
\hline S. Typhi & 22 & $\begin{array}{l}\text { 2005-2006; } \\
\text { North India }\end{array}$ & $16->32$ & [36] \\
\hline
\end{tabular}

Third-generation cephalosporins, particularly ceftriaxone, have remained as the viable alternative in the treatment of typhoid fever in this country and elsewhere. In this case report the particular strain involved was also sensitive to ceftriaxone but this may not remain the case. Already there are reports of extended spectrum beta-lactamase (ESBL)-mediated cephalosporin resistance in non-typhoidal Salmonellae from many centres including ours $[37,38]$. It is only a matter of time before these genes encoding ESBLs will cross over to the typhoidal Salmonellae and cause resistance to ceftriaxone. Indeed this is already being reported from Pakistan and Bangladesh $[39,40]$.

The emergence of $S$. Typhi highly resistant to ciprofloxacin further emphasizes the importance of the prudent use of antibiotics.

\section{References}

1. The World Health Report, Report of the Director General WHO (1996) World Health Organisation: Geneva.

2. Cooke FJ, Wain J (2004) The emergence of antibiotic resistance in typhoid fever. Travel Med Infect Dis 2:67-74.

3. Jesudason MV, John TJ (1992) Plasmid mediated multidrug resistance in Salmonella Typhi. Indian J Med Res 95:66-67.

4. Butt T, Ahmad RN, Mahmood A, Zaidi S (2003) Ciprofloxacin treatment failure in typhoid fever case, Pakistan. Emerg Infect Dis 9:1621-1622.

5. Eykyn SJ, Williams H (1987) Treatment of multiresistant Salmonella typhi with oral ciprofloxacin. Lancet ii, 14071408.

6. Mandal BK (1991) Modern treatment of typhoid fever. J Infect 22:1-4.

7. Sanghavi SK, Mane MP, Niphadkar KB (1999) Multidrug resistance in Salmonella serotypes. Indian J Med Microbiol 17:88-90.

8. Chande C, Shrikhande S, Kapale S, Agrawal S, Fule RP (2002) Change in antimicrobial resistance pattern of Salmonella Typhi in central India. Indian J Med Res 115:248-250.

9. Saha MR, Dutta P, Niyogi SK, Dutta S, Mitra U, Ramamurthy T, Manna B, Bhattacharya SK (2002) Decreasing trend in the occurrence of Salmonella enterica serotype Typhi amongst hospitalized children in Kolkata, India during 1990-2000. Indian J Med Res 115:46-48.

10. Kumar R, Aneja KR, Roy P, Sharma M, Gupta R, Ram S (2002) Evaluation of minimum inhibitory concentration of quinolones and third generation cephalosporins to Salmonella Typhi isolates. Indian J Med Sci 56:1-8.

11. Ackers ML, Puhr ND, Tauxe RV, Mintz ED (2000) Laboratory-based surveillance of Salmonella serotype Typhi infections in the United States: antimicrobial resistance on the rise. JAMA 283:2668-2673.

12. Rahman M, Ahmad A, Shoma S (2002) Decline in epidemic of multidrug resistant Salmonella Typhi is not associated with increased incidence of antibioticsusceptible strain in Bangladesh. Epidemiol Infect 129:29-34.

13. Threlfall EJ, Ward LR (2001) Decreased susceptibility to ciprofloxacin in Salmonella enterica serotype Typhi, United Kingdom. Emerg Infect Dis 7:448-450.

14. Asna SM, Haq JA, Rahman, M. (2003) Nalidixic acidresistant Salmonella enterica serovar typhi with decreased susceptibility to ciprofloxacin caused treatment failure: a report from Bangladesh. Jpn J Infect Dis 56:3233.

15. Baliga S, Shenoy S, Vidyalaxmi K, Pereira P (1999) Ciprofloxacin resistant Salmonella typhi. Natl Med J India 12:138.

16. Bhat KG, Suresh K. Ciprofloxacin-resistant Salmonella Typhi (1999) Natl Med J India 12:88.

17. Jesudason MV, Malathy B, John TJ (1996) Trend of increasing levels of minimum inhibitory concentration of ciprofloxacin to Salmonella Typhi. Indian J Med Res 103:247-249. 
18. Harish BN, Madhulika U, Parija SC (2004) Current pattern in antimicrobial susceptibility of Salmonella Typhi isolates in Pondicherry. Indian J Med Res 120:111-114.

19. Turner AK, Nair S, Wain J (2006) The acquisition of full fluoroquinolone resistance in Salmonella Typhi by accumulation of point mutations in the topoisomerase targets. J Antimicrob Chemother 58:733-740.

20. Nair S, Unnikrishnan M, Turner K, Parija SC, Churcher C, Wain, J, Harish BN (2006) Molecular analysis of fluoroquinolone resistant Salmonella Paratyphi A isolates, India. Emerg Infect Dis 12(3):489-491.

21. Aarestrup FM, Molbak K, Threlfall E.J (2003) Is it time to change fluoroquinolone breakpoints for Salmonella spp.? Antimicrob Agents Chemother 47:827-829.

22. Kapil A, Sood S, Dash NR, Das BK, Seth P (1999) Ciprofloxacin in typhoid fever. Lancet 354:164.

23. NCCLS (2002) Performance Standards for Antimicrobial Disc Susceptibility Tests, 7th edn. Approved standard M2-A7. Wayne, PA: NCCLS.

24. Kapil, A., Renuka, K. \& Das, BK (2002) Nalidixic acid susceptibility test to screen ciprofloxacin resistance in Salmonella typhi. Indian J Med Res 115:49-54.

25. Harish BN, Madhulika U, Parija SC (2004) Isolated highlevel ciprofloxacin resistance in Salmonella enterica subsp. enterica serotype Paratyphi A. J Med Microbiol 53:819.

26. Harish BN, Menezes GA, Sarangapani K, Parija SC (2006) Fluoroquinolone resistance among Salmonella enterica serovar Paratyphi A, in Pondicherry. Indian J Med Res 124:585-587.

27. NCCLS (1973) Performance Standards for Antimicrobial Susceptibility Testing. 4th International Supplement, 2-74. Wayne, PA: NCCLS.

28. Dutta S, Sur D, Manna B, Sen B, Bhattacharya M, Bhattacharya SK, Wain J, Nair S Clemens JD, Ochiai RL (2008) Emergence of highly fluoroquinolone-resistant Salmonella enterica serovar Typhi in a community-based fever surveillance from Kolkata, India. Int J Antimicrob Agents 31:387-389

29. Raveendran R, Wattal C, Sharma A, Oberoi J K, Prasad K J, Datta S (2008) High level ciprofloxacin resistance in Salmonella enterica isolated from blood. Indian $\mathrm{J}$ Med Microbiol 26:50-53

30. Kownhar H, Shanker EM, Rajan R, Rao UA (2007) Emergence of nalidixic acid-resistant Salmonella enterica serovar Typhi resistant to ciprofloxacin in India. J Med Microbiol 56:136-137.

31. Gaind R, Paglietti B, Murgia M, Dawar R, Uzzau S, Cappuccinelli P, Deb M, Aggarwal1 P, Rubino S (2006) Molecular characterization of ciprofloxacin-resistant Salmonella enterica serovar Typhi and Paratyphi A causing enteric fever in India. J Antimicrob Chemother 58:1139-1144.

32. Daga MK, Sarin K, Sarkar R (1994) A study of culture positive multidrug resistant enteric fever--changing pattern and emerging resistance to ciprofloxacin. J Assoc Physicians India 42:599-600.

33. Renuka K, Sood S, Das BK, Kapil A (2005) High-level ciprofloxacin resistance in Salmonella enterica serotype Typhi in India. J Med Microbiol 54:999-1000.

34. Gaind R, Paglietti B, Murgia M, Dawar R, Uzzau S, Cappuccinelli P, Deb M, Aggarwal1 P, Rubino S (2006) Molecular characterization of ciprofloxacin-resistant
Salmonella enterica serovar Typhi and Paratyphi A causing enteric fever in India. J Antimicrob Chemother 58:1139-1144.

35. Capoor RM, Nair D, Deb M, Aggarwal P (2007) Enteric fever perspective in India: emergence of high-level ciprofloxacin resistance and rising MIC to cephalosporins. J Med Microbiol 56:1131-1132.

36. Raveendran R, Wattal C, Sharma A, Oberoi J K, Prasad K J, Datta S (2008) High level ciprofloxacin resistance in Salmonella enterica isolated from blood. Indian $\mathrm{J}$ Med Microbiol 26:50-53.

37. Menezes GA, Harish BN, Parija SC (2008) A case of fatal acute pyogenic meningitis in a neonate caused by extended spectrum $\beta$-lactamase producing Salmonella Group B. Jpn J Infect Dis 61:234-235.

38. Hohmann EL (2001) Nontyphoidal salmonellosis. Clin Infect Dis 32:263-269.

39. Mushtaq MA (2006) What after ciprofloxacin and ceftriaxone in treatment of Salmonella typhi. Pak J Med Sci 22:51-54.

40. Saha SK, Talukder SY, Islam M, Saha S (1999) A highly ceftriaxone-resistant Salmonella typhi in Bangladesh. Pediatr Infect Dis J 18:387.

Corresponding Author: BN Harish, Professor, Dept of Microbiology, Jawaharlal Institute of Postgraduate Medical Education and Research, Pondicherry 605006, India, Phone: 9443413502, Fax: 0413-2272067, Email:drbnharish@yahoo.com

Conflict of interest: No conflict of interest is declared. 